\title{
Impact of a Tapered Design in the Performance of Diffusion Flame Reactors
}

\author{
A. C. Klemz ${ }^{1 \dagger}$, É. Fontana ${ }^{2}$, A. A. U. de Souza ${ }^{1}$ and S. M. A. G. U. de Souza ${ }^{1}$ \\ ${ }^{1}$ Chemical Engineering Program, Federal University of Santa Catarina, 88040-970 Florianópolis, SC, \\ Brazil \\ ${ }^{2}$ Chemical Engineering Program, Federal University of Paraná, 81531-990 Curitiba, PR, Brazil
}

†Corresponding Author Email: anacarolinek@gmail.com

(Received February 7, 2020; accepted July 1, 2020)

\begin{abstract}
Several research projects developed processes for precise nanoparticle positioning with high production rates. Among the gas phase manipulation strategies, the study of the inertial properties received special attention for the fabrication of nanostructured systems. In particular, aerodynamic focusing technique has allowed particles concentration onto a single streamline, improving collimated particle beam formation and opening new perspectives for nanoparticles production in the gas phase. In this paper, the influence of the reactor design was investigated, particularly in respect to the gas phase characteristics, aiming to improve the nanoparticles focusing. It was observed that a concentrated beam can be obtained in the new tapered reactor design without significantly affect the production rate and temperature profile. In addition, the coupling of aerodynamic lenses to the tapered reactor was also investigated, showing that the flow can be better focused at the cost of an increase in the average temperature and pressure drop.
\end{abstract}

Keywords: Diffusion flame reactor; Computational Fluid Dynamics; Combustion; Nanoparticle focusing; Aerodynamic lens system.

\section{INTRODUCTION}

Concentrated particles streams have been used in many applications including nanostructured films assembled from nanoparticles generated in the gas phase. Typical applications of this technology include battery electrodes (Lee et al. 2008; Ochs et al. 2011), gas sensors (Barborini et al. 2008; Mädler et al. 2006), supercapacitors (Bongiorno et al. 2006; Diederich et al. 1999), fuel cells (Athanassiou et al. 2010) and high density magnetic recording medias (Qiu et al. 2005; Wegner et al. 2012). To this end, several researchers developed processes for precise nanoparticle positioning with high production rates (Choi et al. 2015; Wegner et al. 2006).

Gas phase synthesis is a well-developed technique used for the fabrication of nanostructured systems with high production rates and good control of the particle physicochemical properties (Wegner et al. 2002; Yu et al. 2008). However, the nanoparticles synthesis in the gas phase generally does not produce monodisperse particles. Instead, it generates particles with a size distribution that depends mainly on the reactor conditions (Yu et al. 2008). Among the gas phase manipulation strategies (including the ability to control position, size and velocity of the nanoparticles), the study of the inertial properties have received special attention for the fabrication of nanostructured systems (Piseri et al. 2004).

The nanoparticle focusing was initially studied by the use of capillary tubes (Dahneke \& Flachsbart 1972; Murphy \& Sears, 1964), thin-plate orifices (Das \& J. Phares 2004; Deng et al. 2008), and conical contraction nozzles (Chen and Pui 1995). However, due to the narrow opening for nanoparticle-size classification, the use of these techniques are limited (Zhang et al. 2016). On the other hand, the aerodynamic lens focusing technique, first designed by Liu et al. (1995a, 1995b), has permitted the particle concentration onto a single streamline near to the system axis, improving the collimated particle beam formation with high flow rates (Headrick et al. 2013; Wang et al. 2005b). The term "aerodynamic lenses" refers to a sequence of narrow passages that can be used to focus the main flow, in analogy with optical lenses. Thereby, the aerodynamic 


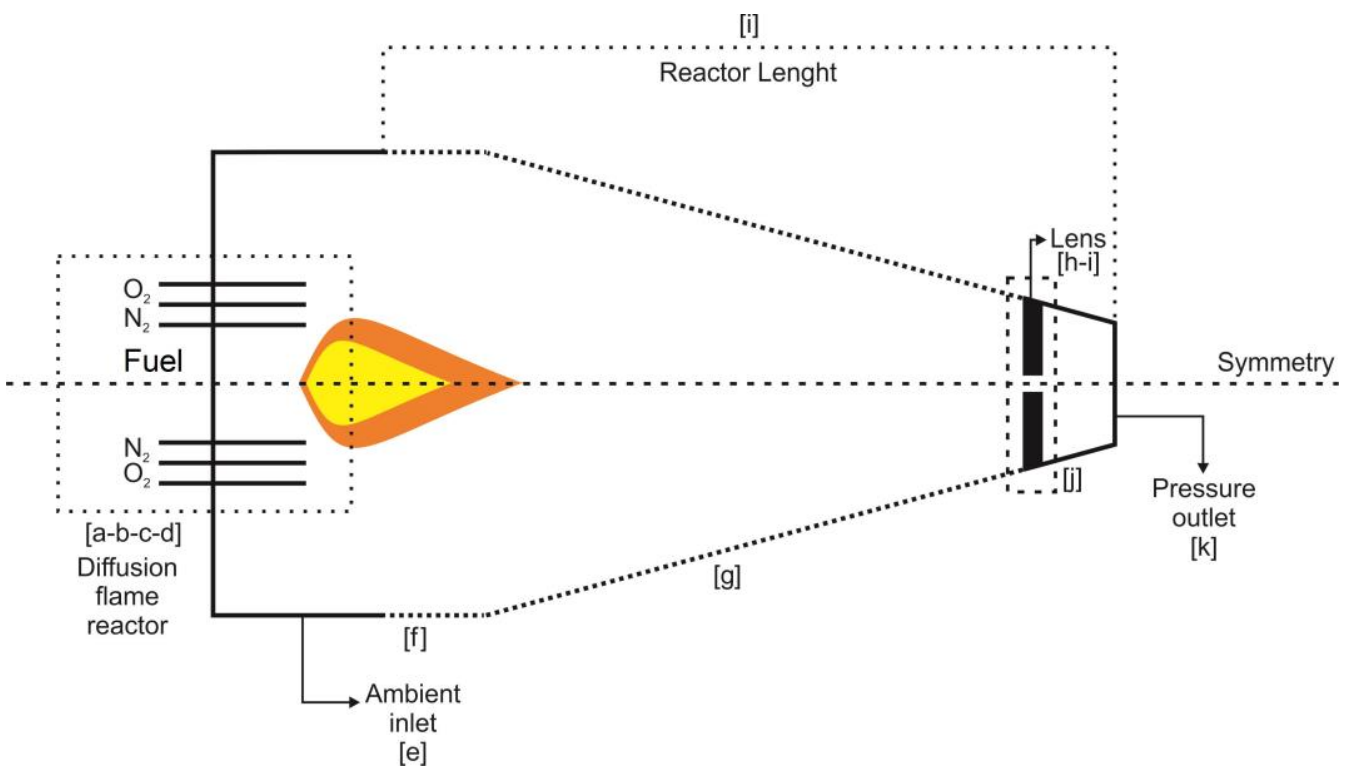

Fig. 1. Diffusion flame reactor dimensions with an aerodynamic lens.

manipulation improvement allows new perspectives for the production of nanoparticles in the gas phase (Mazza et al. 2005; Wegner et al. 2006).

To evaluate the performance of an aerodynamic lens system, Liu et al. (1995a, 1995b, 2007) conducted theoretical, numerical, and experimental studies. Based on the numerical model presented by Liu et al. (1995a, b), Zhang et al. $(2004,2002)$ proposed a new compressible flow model. Wang et al. (2005a) evaluated the flow and the particle transport in a lens system considering the particle Brownian motion with a numerical approach in order to evaluate the particle loss and the beam broadening due to diffusion. Wang and McMurry (2006) reported in their study the development of a tool used to design and evaluate aerodynamic lens systems based on the following parameters: pressure-limiting orifice, relaxation chamber, focusing lenses, spacers and accelerating nozzles. The authors also provided estimations of the particles axial velocities, particle beam width and particles transmission efficiencies. Considering the gas phase synthesis, Klemz et al. (2017) carried out a numerical investigation of different arrangements of a diffusion flame reactor coupled to an aerodynamic lens system for nanoparticle functional nanofilm production. The use of a lens system allowed a significant improvement in the particles focusing, since the main flow could be restricted to a region three times smaller compared to the equivalent region in the diffusion flame reactor without lenses.

Although several investigations were made about the nanoparticles inertial properties and the aerodynamic manipulation, few studies involving the modeling and simulation of the use of thin orifice plates or aerodynamic lenses coupled with flame reactors were performed. Moreover, in most cases, the reactor chamber is assumed to have a constant cross sectional area, so that the gaseous species flow with an approximately constant average velocity. When the process goal is to synthesize nanoparticles and the flow field control is not the main issue, the use of simpler configurations is acceptable. However, when the particles focusing is required, the impact of the entire reactor design in the particles distribution is significant and cannot be neglected as a tool for process optimization. Thus, aiming to improve the reactor performance and the particle focusing, a new tapered diffusion flame reactor was numerically evaluated, including cases with focusing lenses. The main objective was to define arrangements that guarantees a concentrated particles stream without the use of very low pressures at the system outlet, decreasing the operational cost and facilitating the system implementation. The effect of the reactor design in the gas phase characteristics was studied, allowing the definition of the best operational condition for specific applications.

\section{PHYSICAL PROBLEM AND NUMERICAL IMPLEMENTATION}

In this work, different diffusion flame reactors designed for nanoparticle production and focusing were compared. The design was based in the conventional reactor evaluated by Mueller et al. (2004), which studied the synthesis of silica $\left(\mathrm{SiO}_{2}\right)$ nanoparticles. This reactor is basically formed by a radially symmetric stainless steel burner consisting of three concentric tubes, where the fuel $\left(\mathrm{N}_{2} / \mathrm{CH}_{4} /\right.$ hexamethyldisiloxane-HMDSO) stream is supplied in the center tube while the inert $\left(\mathrm{N}_{2}\right)$ and oxidant $\left(\mathrm{O}_{2}\right)$ streams are supplied in the first and second annulus, respectively.

The new design was based on the variation of the diffusion flame reactor transversal section, as seen in Fig. 1. First, the effect of this geometric change in the main flow was evaluated with operating (outlet) pressures of $0.5,0.75$ and $1 \mathrm{~atm}$. In these cases, no aerodynamic lens was considered. The subsequent 
numerical cases included the study of the new reactor geometry coupled with one aerodynamic lens, which consists in one orifice plate with a central bore, positioned about $50 \mathrm{~mm}$ upstream the reactor outlet. Then, the influence of the lens presence was investigated with operating pressures of $0.5,0.75 \mathrm{~atm}$ and $0.95 \mathrm{~atm}$, since at $1 \mathrm{~atm}$ the pressure gradient was not sufficient to induce the flow passage through the orifice, generating a strong backflow upstream the lens. Finally, the coupling of the tapered diffusion flame reactor with 2, 3 or 4 aerodynamic lenses (L), at operating pressures of $0.5,0.75 \mathrm{~atm}$ and $0.95 \mathrm{~atm}$, was studied. The last lens remained at $50 \mathrm{~mm}$ upstream the reactor outlet while the other lenses were equidistantly placed (with $146 \mathrm{~mm}$ below the last lens). Figure 1 illustrates the new reactor geometry, with the different inlets (Fuel $/ \mathrm{N}_{2} / \mathrm{O}_{2} /$ ambient air) and the locations associated with the lenses. The diffusion flame reactor dimensions are presented in Table 1.

Table 1 Diffusion flame reactor dimensions.

\begin{tabular}{|c|c|}
\hline Boundary & Size \\
\hline $\begin{array}{c}\text { a) Center tube inner-outer } \\
\text { diameters }\end{array}$ & $0-4.8(\mathrm{~mm})$ \\
\hline $\begin{array}{c}\text { b) First annulus inner-outer } \\
\text { diameters }\end{array}$ & $5.6-6.4(\mathrm{~mm})$ \\
\hline $\begin{array}{c}\text { c) Second annulus inner-outer } \\
\text { diameters }\end{array}$ & $7.3-9(\mathrm{~mm})$ \\
\hline d) Burner length & $0.013(\mathrm{~m})$ \\
\hline e) Ambient inlet & $0.03(\mathrm{~m})$ \\
\hline f) Reactor wall & $30(\mathrm{~mm})$ \\
\hline g) Conical wall & $0.522(\mathrm{~m})$ \\
\hline h) Lens diameter & $3.0(\mathrm{~mm})$ \\
\hline i) Lens thickness & $2.0(\mathrm{~mm})$ \\
\hline j) Side wall & $50.23(\mathrm{~mm})$ \\
\hline k) Pressure outlet diameter & $15(\mathrm{~mm})$ \\
\hline 1) Reactor length & $0.60(\mathrm{~m})$ \\
\hline
\end{tabular}

Due to the small size and low particle concentration, it was assumed that the formation of the nanoparticles after the vaporization and combustion of the precursor and its dynamics had no significant influence on the flow and temperature fields (Noriler et al. 2014). Moreover, it was assumed that the particles will be carried by the fluid flow and follow the streamlines. The validity of these hypotheses for cases with aerodynamic lenses was discussed in the Results Section.

In order to predict the main phenomena of heat and mass transfer under turbulent flow conditions and chemical reactions, the equations discretization was approached by the pressure-based method, where the velocity field was obtained from the moment equations. The turbulent conditions were represented by average Navier-Stokes equations assuming the turbulent viscosity hypothesis, calculated by the realizable $\mathrm{k}-\varepsilon$ turbulence model with a second-order pressure discretization. To model the turbulencechemistry interactions, seven species were included in the: methane $\left(\mathrm{CH}_{4}\right)$, carbon dioxide $\left(\mathrm{CO}_{2}\right)$, water $\left(\mathrm{H}_{2} \mathrm{O}\right)$, hexamethyldisiloxane - HMDSO $\left(\mathrm{C}_{6} \mathrm{H}_{18} \mathrm{OSi}{ }_{2}\right)$, nitrogen $\left(\mathrm{N}_{2}\right)$, oxygen $\left(\mathrm{O}_{2}\right)$ and silica $\left(\mathrm{SiO}_{2}\right)$ (Klemz et al. 2017). The temperature was considered as $300 \mathrm{~K}$ at all boundaries and gravity was included in the model, acting in the negative $\mathrm{x}$ direction. The boundary conditions are presented in Table 2.

Table 2 Boundary conditions

\begin{tabular}{|c|c|c|}
\hline Boundary & Velocity/Pressure* & $\begin{array}{c}\text { Molar } \\
\text { composition } \\
(\%)^{*}\end{array}$ \\
\hline Oxygen inlet & $17.4 \mathrm{~m} / \mathrm{s}$ & $\mathrm{O}_{2}: 100 \%$ \\
\hline $\begin{array}{c}\text { Nitrogen } \\
\text { inlet }\end{array}$ & $1.11 \mathrm{~m} / \mathrm{s}$ & $\mathrm{N}_{2}: 100 \%$ \\
\hline $\begin{array}{c}\text { Fuel inlet } \\
\text { Wall }\end{array}$ & $3.96 \mathrm{~m} / \mathrm{s}$ & $\begin{array}{c}\mathrm{N}_{2}: 66.05 ; \mathrm{CH}_{4}: \\
32.60 ; \mathrm{HMDSO}^{1.35 \%}\end{array}$ \\
\hline $\begin{array}{c}\text { Ambient } \\
\text { inlet/ }\end{array}$ & 0 & - \\
$\begin{array}{c}\text { Reactor } \\
\text { chamber } \\
\text { pressure }\end{array}$ & $1 \mathrm{~atm}$ & $\mathrm{~N}_{2}: 79 ; \mathrm{O}_{2}: 21 \%$ \\
\hline Outlet & $0.5-1 \mathrm{~atm}$ & - \\
\hline
\end{tabular}

* Mueller et al. 2004

The numerical simulations were performed considering the finite volume method using the Ansys Fluent code through the implementation of a two-dimensional axisymmetric structured mesh. The numerical solution dependence on the grid resolution was verified according to the temperature and fuel conversion profiles and it was found that a mesh with 130,000 elements was suitable to achieve the convergence criteria of $10^{-5}$. The hexahedral elements mesh structure is represented in the Fig. 2. The elements were concentrated on the reactor centerline to precisely assess the main phenomena.

\subsection{Governing Equations}

In this section, the basic set of governing equations for the flow modeling are presented. The model considers the continuous gas phase in an Eulerian approach (continuity, momentum, energy and chemical species equations) under steady-state conditions and compressible turbulent flow. The governing equations for the momentum and energy distribution were the common Navier-Stokes and total energy conservation, respectively. For further details, readers are referred to the software manuals (Fluent, 2011).

\section{Continuity equation:}

$$
\nabla \cdot(\rho \vec{v})=0
$$

Momentum conservation equations:

$$
\nabla \cdot(\rho \vec{v} \vec{v})=-\nabla p+\nabla \cdot\left(\overline{\bar{\tau}}+\overline{\overline{\tau_{t}}}\right)
$$




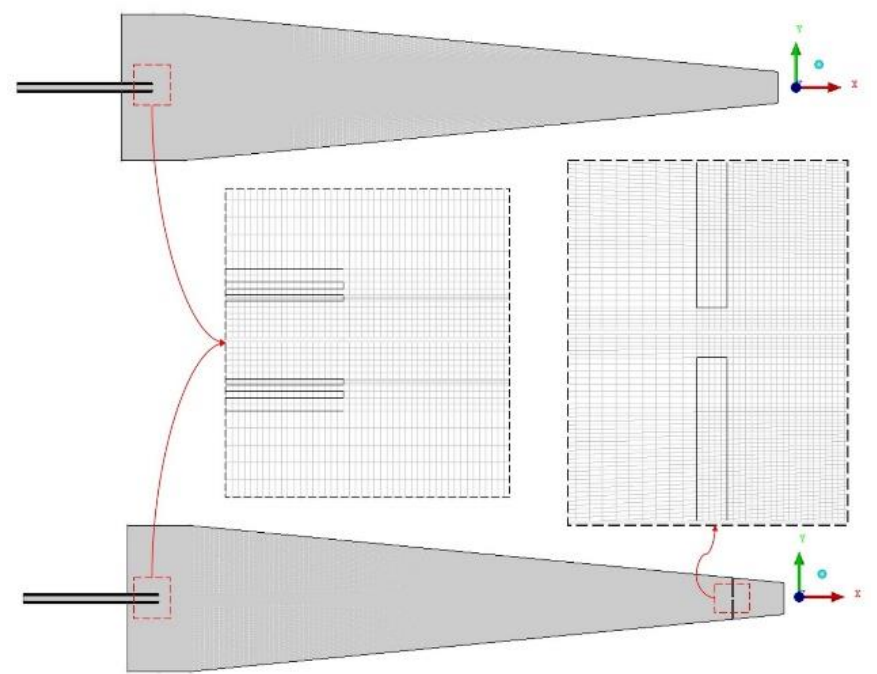

Fig. 2. Mesh structure representation for the tapered flame reactor with and without aerodynamic lens.

where $p$ is the static pressure, $\overline{\bar{\tau}}$ is the stress tensor and is given by:

$\overline{\bar{\tau}}=\mu\left[\left(\nabla \vec{v}+\nabla \vec{v}^{T}\right)-\frac{2}{3} \nabla \cdot \vec{v} I\right]$

where $\mu$ is the molecular viscosity, $I$ is the unit tensor, and the second term on the right-hand side is the effect of volume dilation.

Turbulence equations: The $\mathrm{k}-\varepsilon$ model is based on transport equations for the turbulence kinetic energy (k) and its dissipation rate $(\varepsilon)$, given by:

$\frac{\partial}{\partial t}(\rho k)+\frac{\partial}{\partial x_{j}}\left(\rho k u_{j}\right)=\frac{\partial}{\partial x_{j}}\left[\left(\mu+\frac{\mu_{t}}{\sigma_{k}}\right) \frac{\partial k}{\partial x_{j}}\right]+G_{k}+$

$G_{b}-\rho \varepsilon-Y_{M}$

and

$\frac{\partial}{\partial t}(\rho \varepsilon)+\frac{\partial}{\partial x_{j}}\left(\rho \varepsilon u_{j}\right)=\frac{\partial}{\partial x_{j}}\left[\left(\mu+\frac{\mu_{t}}{\sigma_{\varepsilon}}\right) \frac{\partial \varepsilon}{\partial x_{j}}\right]+$

$\rho C_{1} S \varepsilon-\rho C_{2} \frac{\varepsilon^{2}}{k+\sqrt{v \varepsilon}}+C_{1 \varepsilon} \frac{\varepsilon}{k} C_{3 \varepsilon} G_{b}$

where $G_{k}$ represents the generation of turbulence kinetic energy due to the mean velocity gradients, $G_{b}$ is the generation of turbulence kinetic energy due to buoyancy, $C_{1}, C_{2}$ and $C_{1 \varepsilon}$ are constants, $\sigma_{k}$ and $\sigma_{\varepsilon}$ are the turbulent Prandtl numbers for $k$ and $\varepsilon$, respectively. $Y_{M}$ represents the contribution of the fluctuating dilatation in compressible turbulence to the overall dissipation rate, given by:

$Y_{M}=2 \rho \varepsilon M_{t}^{2}$

where $M_{t}$ is the turbulent Mach number:

$M_{t}=\sqrt{\frac{k}{a^{2}}}$

where $a(\equiv \sqrt{\gamma R T})$ is the speed of sound.

Turbulent Viscosity: the eddy viscosity is given by:

$\mu_{t}=\rho C_{\mu} \frac{k^{2}}{\varepsilon}$

Energy equations: the turbulent heat transport is modeled using the concept of Reynolds' analogy to turbulent momentum transfer, given by:

$\frac{\partial}{\partial t}(\rho E)+\frac{\partial}{\partial x_{i}}\left[u_{i}(\rho E+p)\right]=\frac{\partial}{\partial x_{j}}\left(k_{e f f} \frac{\partial T}{\partial x_{j}}+\right.$

$\left.u_{i}\left(\tau_{i i}\right)_{e f f}\right)+S_{h}$

where $E$ is the total energy, $k_{e f f}$ is the effective thermal conductivity, and $\left(\tau_{i i}\right)_{e f f}$ is the deviatoric stress tensor, defined as:

$\left(\tau_{i i}\right)_{e f f}=\mu_{e f f}\left(\frac{\partial u_{j}}{\partial x_{i}}+\frac{\partial u_{i}}{\partial x_{j}}\right)-\frac{2}{3} \mu_{e f f} \frac{\partial u_{k}}{\partial x_{k}} \delta_{i j}$

where $\left(\tau_{i i}\right)_{e f f}$ represents the viscous heating.

The effective thermal conductivity is given by:

$k_{\text {eff }}=k+\frac{C_{p} \mu_{t}}{P r_{t}}$

where $k$, in this case, is the thermal conductivity and $\mathrm{Pr}_{t}$ is the turbulent Prandtl number for energy.

Species transport equations: Non-premixed modeling involves the solution of transport equations for one or two conserved scalars, the mixture fractions. Equations for individual species were not solved. Instead, species concentrations were derived from the predicted mixture fraction fields. Interaction of turbulence and chemistry was accounted for with an assumed-shape Probability Density Function (PDF) (Fluent, 2011). The mixture fraction can be written in terms of the atomic mass fraction as:

$f=\frac{Z_{i}-Z_{i, o x}}{Z_{i, f u e l}-Z_{i, o x}}$

where $Z_{i}$, is the elemental mass fraction for element, $i$. The subscript $o x$ and the subscript fuel are the value at the oxidizer and the fuel stream inlet, respectively.

The Favre mean (density-averaged) mixture fraction equation is:

$\frac{\partial}{\partial t}(\rho \bar{f})+\nabla \cdot(\rho \vec{v} \bar{f})=\nabla \cdot\left(\frac{\mu_{t}}{\sigma_{t}} \nabla \bar{f}\right)+S_{m}$ 


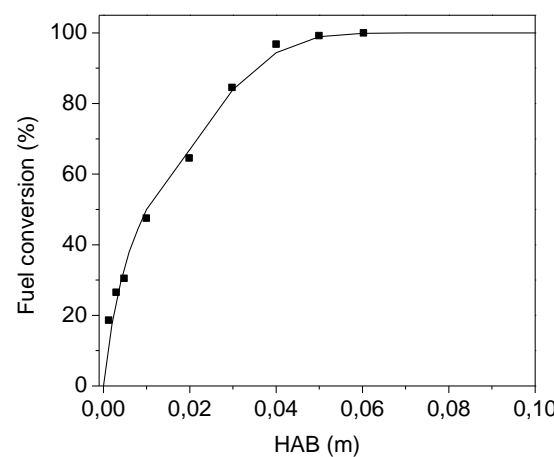

(a)

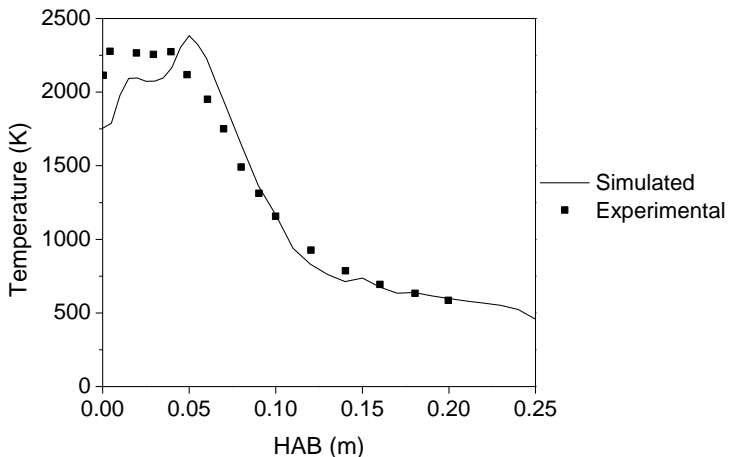

(b)

Fig. 3. Comparison between the experimental results presented by Mueller et al. (2004) and the numerical model proposed for the (a) fuel conversion and (b) temperature along the main axis.

The source term $S_{m}$ is due solely to mass transfer into the gas phase from reacting particles. Moreover, ANSYS Fluent solves a conservation equation for the mixture, fraction variance, $\overline{f^{\prime 2}}$ :

$\frac{\partial}{\partial t}\left(\rho \overline{f^{\prime 2}}\right)+\nabla \cdot\left(\rho \vec{v} \overline{f^{\prime 2}}\right)=\nabla \cdot\left(\frac{\mu_{t}}{\sigma_{t}} \nabla \overline{f^{\prime 2}}\right)+$

$C_{g} \mu_{t}(\nabla \bar{f})^{2}-C_{d} \rho \frac{\varepsilon}{k} \overline{f^{\prime 2}}$

where $f^{\prime}=f-\bar{f}$. The default values for the constants $\sigma_{t}, C_{g}$ and $C_{d}$ are $0.85,2.86$ and 2.0, respectively.

Particle force balance: as an initial hypothesis, the influence of the nanoparticles formation on the flow and temperature fields was neglected (Noriler et al. 2014). In order to verify the validity of this hypothesis, some simulations were done considering inert particles present in the streamflow. In these cases, the particles trajectories were predicted by integrating the force balance on the particle in a Lagrangian reference frame, as shown in Equation 15 for the $x$ direction:

$\frac{\partial u_{p}}{\partial t}=F_{D}\left(\vec{u}-\overrightarrow{u_{p}}\right)+\frac{\vec{g}\left(\rho_{p}-\rho\right)}{\rho_{p}}+\vec{F}$

where $\vec{F}$ is an additional acceleration (force/unit particle mass) term, $F_{D}\left(\vec{u}-\overrightarrow{u_{p}}\right)$ is the drag force per unit particle mass and defined by:

$F_{D}=\frac{18 \mu}{\rho_{p} d_{p}^{2}} \frac{C_{D} R e}{24}$

here, $\vec{u}$ is the fluid phase velocity, $\overrightarrow{u_{p}}$ is the particle velocity, $\mu$ is the molecular viscosity of the fluid, $\rho$ is the fluid density, $\rho_{p}$ is the density of the particle, and $d_{p}$ is the particle diameter. $R e$ is the relative to the Reynolds number, which is defined as:

$R e \equiv \frac{\rho d_{p}\left|\overrightarrow{u_{p}}-\vec{u}\right|}{\mu}$

Fuel conversion: The fuel conversion is obtained at different heights above the burner (HAB) by comparing the unburned fuel mass fraction $\left(\mathrm{CH}_{4}\right.$ and HMDSO) at the burner exit $\left(f_{0}\right)$ and at different points in $\operatorname{HAB}\left(f_{x}\right)$, given by:

fuel conversion $=1-\left(\frac{f_{x}}{f_{0}}\right)$

\subsection{Numerical Validation}

With the objective to validate the mathematical model and the numerical procedure, two-dimensional numerical simulations were made and compared with the experimental data obtained by Mueller et al. (2004) for $\mathrm{SiO}_{2}$ nanoparticle production in a plane reactor. Mueller et al. (2004) generated nonagglomerated silica nanoparticles with $18 \mathrm{~nm}$ in methane/oxygen diffusion flames with high production rates $(17 \mathrm{~g} / \mathrm{h})$ and high oxygen flow rates $(17.4 \mathrm{~m} / \mathrm{s})$, by the oxidation of hexamethyldisiloxane (HMDSO). Figure 3 shows the comparison between the experimental results for the temperature and fuel $\left(\mathrm{CH}_{4}\right.$ and HMDSO) conversion profiles and the results obtained with the numerical procedure presented above. It was observed that both simulated temperature and fuel conversion profiles showed a good agreement with the experimental data, indicating that the combustion reaction was well reproduced by the mathematical model. The difference between the numerical and experimental temperature distributions at small HABs was related to a pre-heating zone, which is in agreement with the literature (Gröhn et al. 2011; Klemz et al. 2017).

The proposed changes in the reactor geometry also included the presence of aerodynamic lenses with relatively small orifices. Thus, the numerical procedure also needs to be able to reproduce accurately the fluid flow through constrictions. The Ansys Fluent ability to simulate single phase flows through constrictions was verified by several authors using a procedure similar to the one used in the present study, as showed by Simpson and Ranade (2018) and Araoye et al. (2017).

\section{RESULTS AND DISCUSSIONS}

\subsection{Tapered Diffusion Flame Reactor Without Lenses}

Figure 4 (a-c) shows the flow field for the tapered reactor without lens, represented by the streamlines at operating (outlet) pressures of $0.5,0.75$ and $1 \mathrm{~atm}$, respectively. With operating pressures of 0.5 and 0.75 atm (Fig. 4-a and Fig. 4-b), the pressure difference between the outlet and the ambient inlet 
induced a strong flow in the axial direction. The streamlines followed the path defined by the reactor design, except for small regions of stagnation near the ambient air inlet, which were a direct result of the flow curvature at this region. With the operating pressure of 1 atm (Fig. 4-c) a different pattern was observed, with the formation of large recirculation zones in the reactor central part. In this case, the ambient inlet and the outlet were at the same pressure, therefore, there was no axial flow induced by the pressure difference. Instead, the axial flow was directly caused by the reactants fed to the reactor. The flow constriction caused a pressure drop after the initial part, allowing the backflow. It is also important to note that even at $1 \mathrm{~atm}$ the main flow followed the $\mathrm{x}$-axis and there was no significant backflow through the ambient air inlets, which was important to allow the nanoparticles to be collected at the reactor outlet. In this case, the recirculation region acted like a focusing mechanism to the reactants.

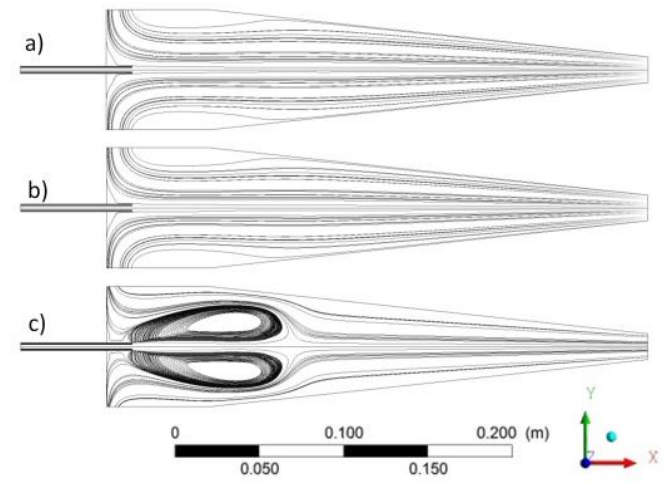

Fig. 4. Streamlines for the tapered reactor without lens, considering operating pressures of a) 0.5 b) 0.75 and c) 1 atm.

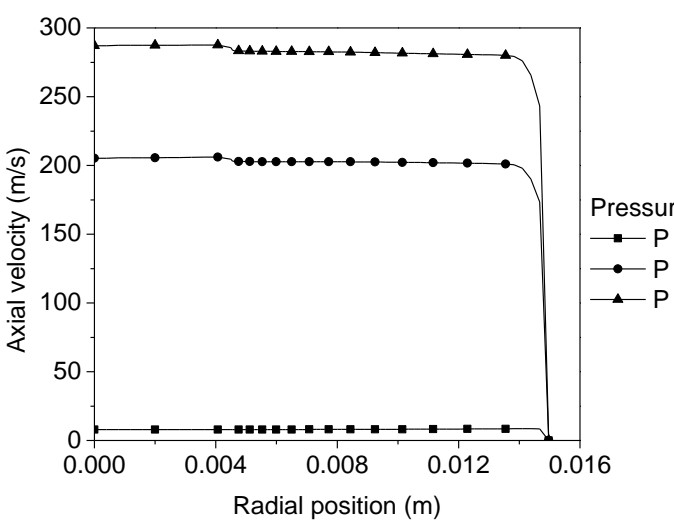

Fig. 5. Axial velocity distribution at the tapered reactor exit considering operating pressures of $0.5,0.75$ and $1 \mathrm{~atm}$

In all cases, with or without axial flow induced by the pressure difference, a similar flow pattern was observed at the reactor exit, as illustrated in Fig. 5 by the axial flow velocity profiles along the radial position. As can be seen, a nearly plug flow profile was obtained with 0.5 and 0.75 atm outlet pressures. With $1 \mathrm{~atm}$, the maximum velocity was reached close to the reactor wall, which was in accordance with the direct flow from the ambient inlet to the outlet, as observed in the streamlines (Fig. 4). Nevertheless, it is important to note that, for all cases, the velocity was practically constant over the entire outlet, which means that there were no significant focusing flow beyond the one caused by the tapered design.

Figure 6 presents the fuel (HMDSO and $\mathrm{CH}_{4}$ ) conversion along the reactor as a function of the height above the burner (HAB) with the different operating (outlet) pressures of $0.5,0.75$ and 1 atm. All cases showed a similar behavior to the observed with the conventional flame reactor (with constant cross sectional area and no lens, Klemz et al. 2017), with values close to $100 \%$ conversion right at the reactor beginning. This indicates that the geometry and operational condition variations did not affect significantly the total fuel conversion, which is important to keep a high production rate. This is the main advantage of the use of a tapered reactor instead of a conventional reactor with smaller diameter, where the residence time is drastically reduced and with the guarantee that the fuel was completely consumed.

Figure 7 shows the temperature profiles along the tapered reactor axis as a function of the HAB with the different operating (outlet) pressures of 0.5, 0.75 and $1 \mathrm{~atm}$. Experimental results with the conventional reactor (with constant cross-sectional area) and operating at $1 \mathrm{~atm}$ were also included for the sake of comparison. The profiles were very similar for the both operating pressures and only a small variation was observed between the cases. Although all cases followed the trend observed in the experimental data used for the model validation, it can be noted that the temperature profile became narrower in the axial direction as the pressure decreases, which is related to the strong flow in the axial direction. This behavior can be better observed in Fig. 8, where the reaction flame became wider as the system pressure increased. The temperature profiles at 1 atm (operating pressure) were similar to the original flame reactor geometry, where a pre-heating zone close to the burner was also observed, which is in agreement with the literature (Gröhn et al. 2011; Klemz et al. 2017). In addition, the use of lower pressures at the system outlet allowed a precise temperature control inside the reactor chamber, a higher flow rate and avoided high temperatures at the walls, reducing the thermal stress.

Although the fuel conversion and the velocity profiles at the outlet did not significantly change, there is an energetic cost associated with the use of lower pressure devices. Fig. 9 presents the static pressure along the reactor central line with different operating (outlet) pressures. In the first reactor, the pressure for all cases is approximately $1 \mathrm{~atm}$ (the inlet pressure), indicating that the reactor is not subjected to any significant mechanical stress. Near the outlet, the pressure quickly drops to the specified value.

Based on the results presented in this section, it is possible to conclude that a tapered reactor allowed the main gas flow focusing without reducing the production rate or significantly changing the temperature profile. This result can be particularly 
A. C. Klemz et al. / JAFM, Vol. 14, No. 1, pp. 201-214, 2021.

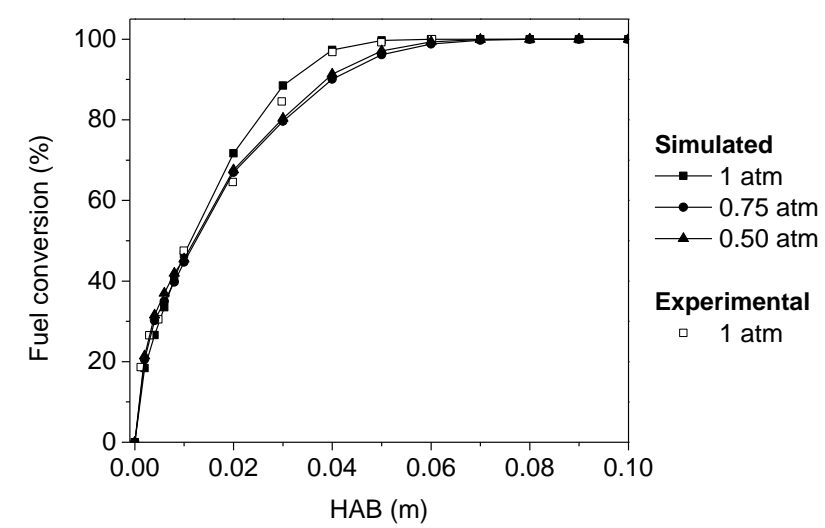

Fig. 6. Fuel (HMDSO and $\mathrm{CH}_{4}$ ) conversion in height above the burner for the tapered reactor, considering operating pressures of $0.5,0.75$ and $1 \mathrm{~atm}$.

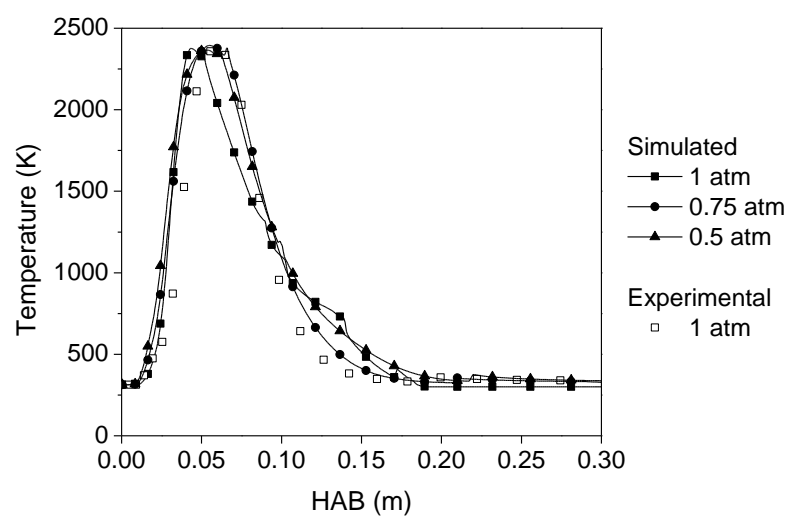

Fig. 7. Temperature profiles in height above the burner (HAB) for the tapered reactor considering operating pressures of 0.5 and $1 \mathrm{~atm}$.

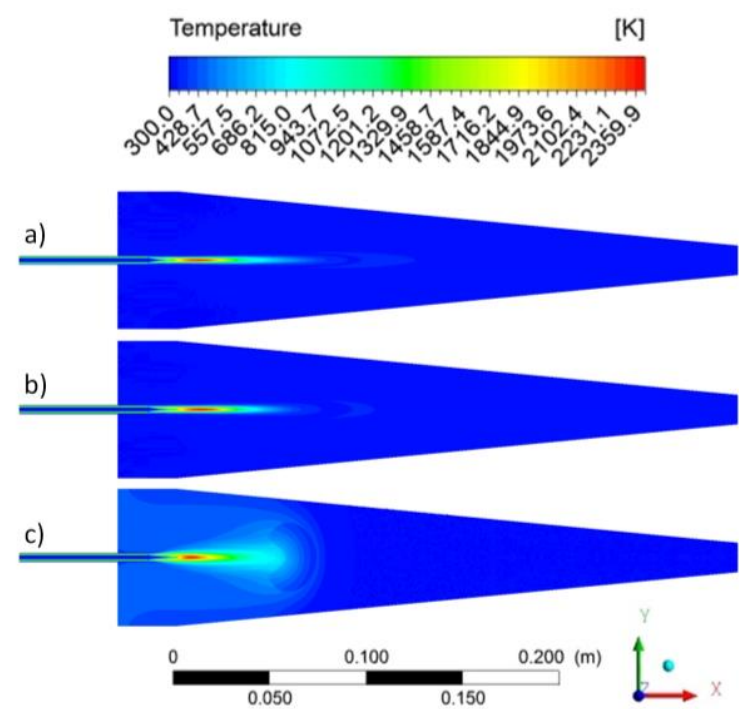

Fig. 8. Temperature contours for the tapered reactor considering operating pressures of $0.5,0.75$ and c) 1 atm.

useful for reactors operating at ambient pressures, since a focused stream can be easily obtained without using pressure-reducing devices, which increase the operational costs and hamper the process. This geometry could be extended, for example, for flame spray reactors, where it is important to maintain a constant $1 \mathrm{~atm}$ pressure condition at the domain outlet (Torabmostaedi \& Zhang 2014; Torabmostaedi et al. 2013; Wegner et al. 2012). 


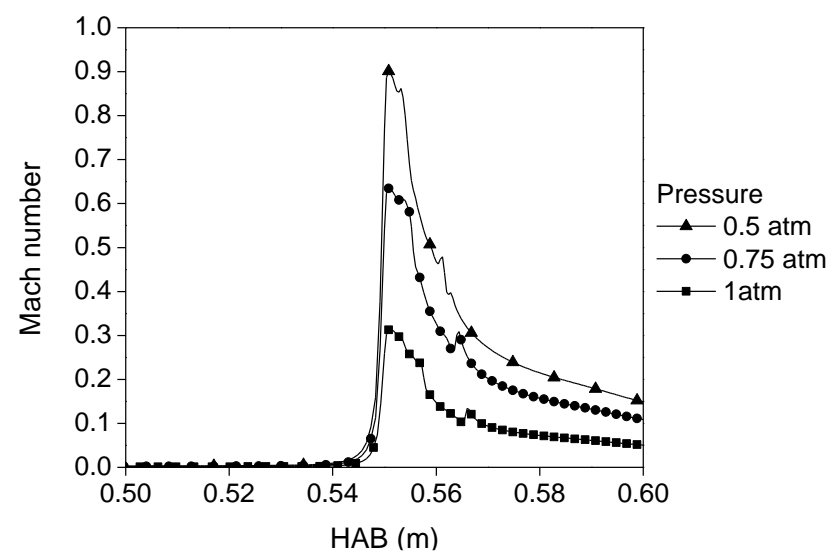

Fig. 11. Mach number profiles in height above the burner (HAB) for the tapered reactor coupled to one lens considering different operating pressures.

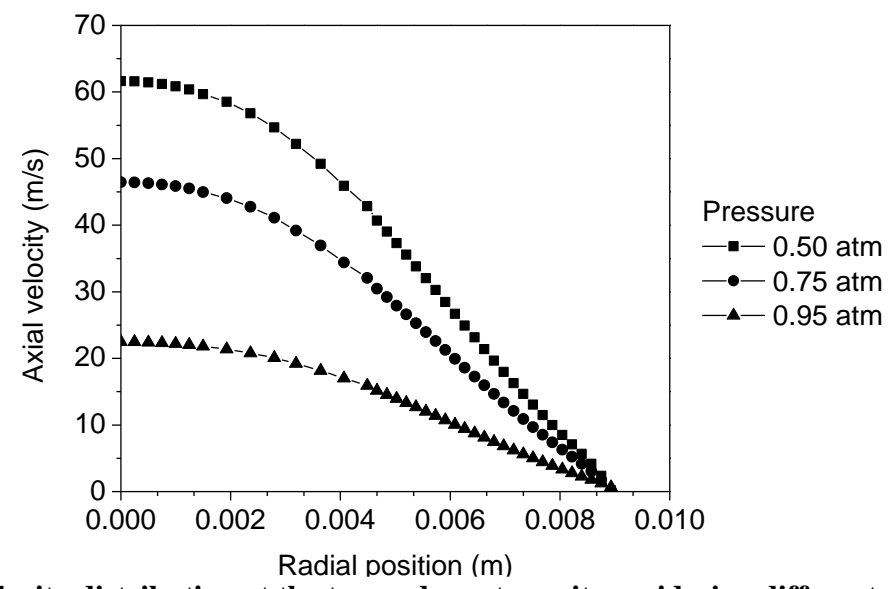

Fig. 12 - Axial velocity distribution at the tapered reactor exit considering different operating pressures and the presence of one orifice plate.

\subsection{Tapered Diffusion Reactor with a Thin Orifice Plate}

Figure 10 (a-c) shows the streamlines for the tapered reactor coupled to one orifice plate close to the outlet, considering operating (outlet) pressures of $0.5,0.75$ and $0.95 \mathrm{~atm}$, respectively. The results with $1 \mathrm{~atm}$ were not presented since, as previously mentioned, the pressure difference was not sufficient to induce a significant flow through the lens. As can be observed, the presence of one orifice plate significantly changed the streamlines pattern, creating large recirculation zones after the ambient air inlet. In this case, the direct axial flow from the air inlet to the reactor outlet was not observed. Instead, the ambient air flowed to the center, increasing the degree of mixing. By comparing Fig. 10-a, Fig. 10-b and Fig. $10-c$, it can be noted that the recirculation zones intensity decreased as the pressure difference between the inlet and the outlet increased. Nevertheless, the different recirculation zones profiles did not exert significant influence on the flow after the lens.

The use of one orifice plate may generates high velocities in the orifice, even close to supersonic speed. The presence of shock waves can significantly harm the process, altering the flow configuration and particle distribution, besides the mechanical stress induced in the walls. In order to verify the presence of supersonic expansion and shock waves, the Mach number (Ma) was calculated at the reactor centerline (in height above the burner - HAB) as shown in Fig. 11, with different operating pressures. For all cases presented, the velocity did not reached the sound velocity and the flow remained subsonic, however, the Mach number reached values up to 0.9 in the orifice passage with 0.5 atm (outlet pressure), indicating that compressibility effects were significant and the assumption of incompressible flow cannot be adopted.

The main objective of the orifice plates use is to focus the flow at the outlet and, as consequence, concentrate the particle distribution. Figure 12 shows the axial velocity profiles in the radial direction at the reactor exit, with operating pressures of $0.5,0.75$ and $0.95 \mathrm{~atm}$. Close to the reactor outlet all cases showed a narrow flow distribution, which indicates that the cross sectional area reduction combined with the orifice plates was suitable to focus the nanoparticles, even with higher outlet reactor pressure. Compared to the initial tapered design (Fig. 5), the orifice plate presence significantly improved the particles 


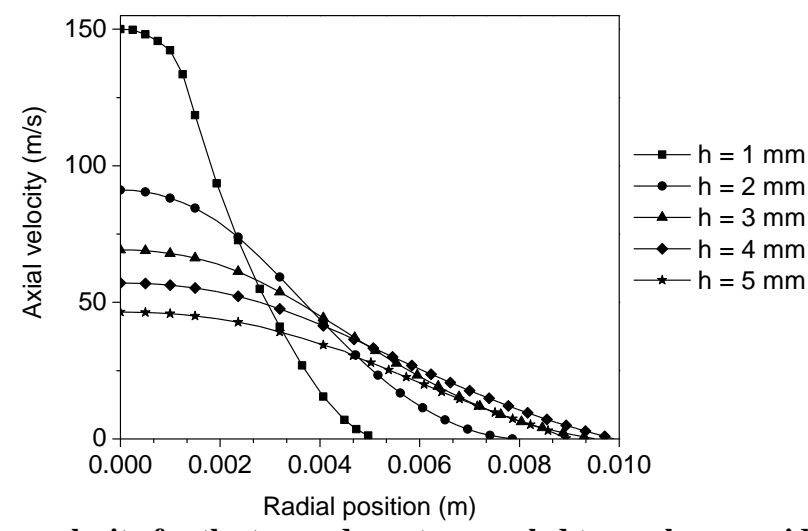

Fig. 13. Axial flow velocity for the tapered reactor coupled to one lens considering an operating pressure of $0.75 \mathrm{~atm}$ and five different height above the lens.

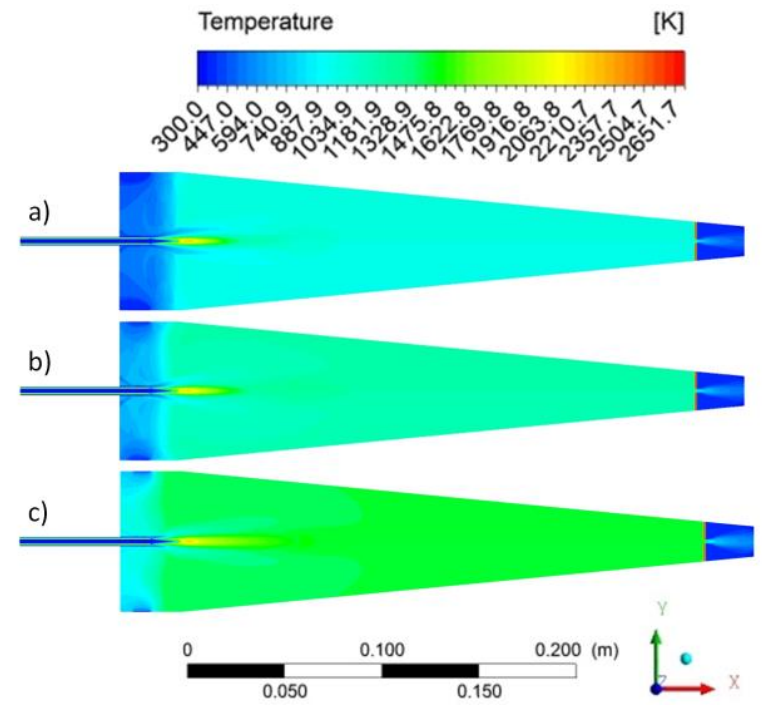

Fig. 14. Temperature contours for the tapered reactor coupled to one lens at operating pressures of a) 0.5 b) 0.75 and c) $0.95 \mathrm{~atm}$.

focusing, restricting the main flow to a region two times smaller. This result represents a very promising approach for the production of nanostructured materials and devices.

In addition, it is worth pointing out that when a narrower flow is desired, the collection chamber can be positioned closer to the lens exit. To illustrate this, Fig. 13 shows the axial velocity distribution at different height above the lens, considering a tapered reactor operating at $0.75 \mathrm{~atm}$. Closer to the lens, the axial flow velocity is higher. However, the flow distribution is considerable narrower, which may be relevant for specific applications.

Since orifice plate presence significantly changed the flow field, it is also important to determine its impact in the reaction kinetics and temperature distribution. Figure 14 (a-c) shows the temperature profiles and Fig. 15 shows the fuel conversion profiles along the tapered reactor considering the different operating pressures. A significant change in the flame profile was observed in Fig. 14 when compared to the tapered reactor without lens (Fig. 8). The recirculation zones caused by the lens suppressed the heat removal, significantly increasing the average temperature in the reaction zone. As can be seen in Fig 12, the velocity at the outlet tends to be much smaller than for the reactor with no orifice plate (Fig. 5), which is also related to the internal recirculation, since this region creates a barrier for the ambient air intake that acts naturally as a coolant. For comparison, the maximum temperature was approximately $300 \mathrm{~K}$ higher than for the reactor without lens. Consequently, the reactor with one lens was subjected to a greater thermal stress, which can reduce the lifespan of the components. Nevertheless, all cases followed the fuel conversion trend of the conventional diffusion flame reactor, which indicates that the orifice plate presence did not significantly affect the total production rate, as illustrated in Fig. 15. Therefore, through the orifice plate coupling, a significant improvement in the particle focusing can be achieved at the cost of an increase in the average temperature inside the reactor and the pressure drop due to the flow constriction. This novel design could be applied to improve the use of cluster beam 


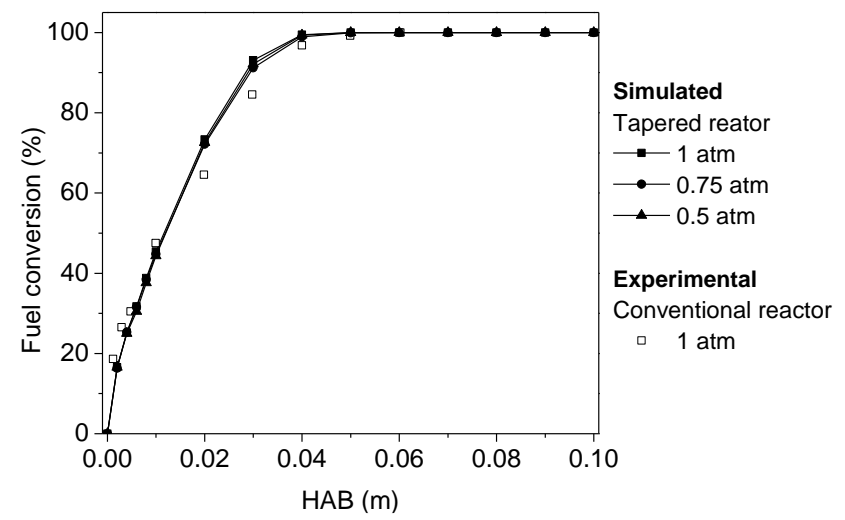

Fig. 15. Fuel (HMDSO and $\left.\mathrm{CH}_{4}\right)$ conversion in height above the burner (HAB) for the tapered reactor coupled to one lens considering different operating pressures.

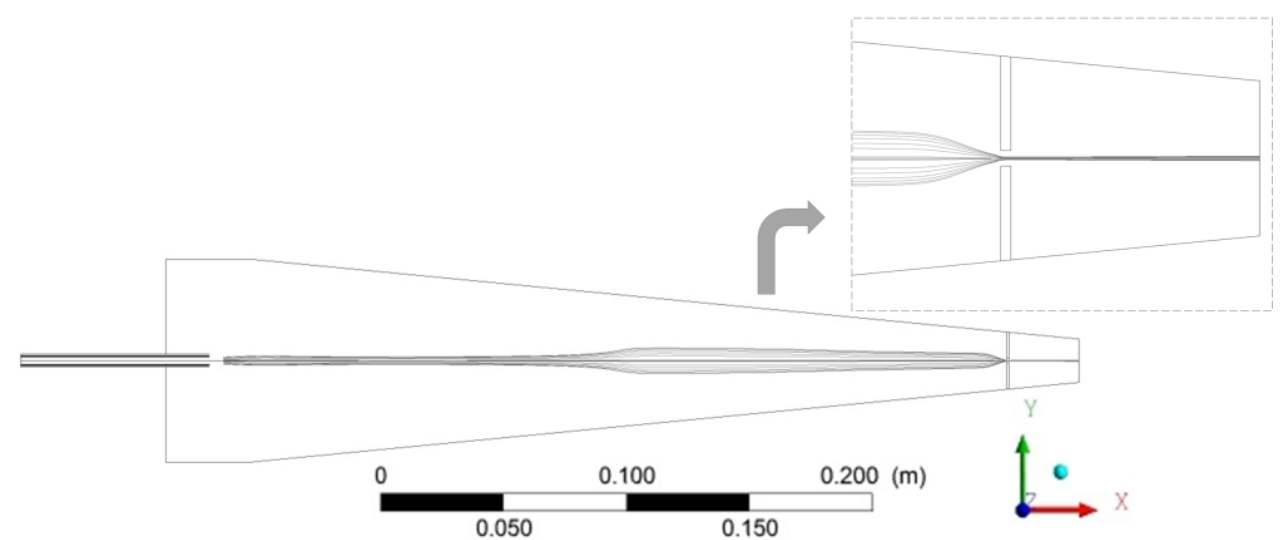

Fig. 16. Trajectories of silica nanoparticles for the tapered reactor coupled to one lens at $0.5 \mathrm{~atm}$ operating pressure.

devices, operating in a subsonic regime, to direct the gas-phase particles onto a specific surface (Milani et al. 2001; Wegner et al. 2006).

As mentioned above, it was assumed that the nanoparticles follow the fluid flow and its influence on the temperature and velocity profiles could be neglected. In order to verify this hypothesis for a tapered reactor with one orifice plate, an analysis with inert nanoparticles was made to assess the system behavior. Silica nanoparticles were injected in a surface $4 \mathrm{~mm}$ above the burner outlet tube, with $2.5 \mathrm{~mm}$ height, since this is approximately the region were the nanoparticles are formed, as described by Mueller et al. (2004). The initial particles velocities were calculated based on the fuel velocity $(3.96 \mathrm{~m} / \mathrm{s})$ while the particle diameter of $18 \mathrm{~nm}$ (uniform diameter distribution) was taken from Mueller et al. (2004) measurements (for a $17 \mathrm{~g} / \mathrm{h}$ production rate and with a $17.4 \mathrm{~m} / \mathrm{s}$ oxygen velocity). Figure 16 illustrates the nanoparticles trajectories represented by the resulting velocity fields at 0.5 atm operating pressure. As can be seen, the silica nanoparticles follow the tapered reactor main flow, even when the velocities are near sonic. Compared to the streamlines (Fig 10-a), it is possible to observe that the recirculation zones helped to keep the particles focused after the inlet, and the flow expansion caused a small expansion in the particles flow near to the center. The particles were not significantly trapped upstream the plate, hence the particle transport efficiency through the exit was not diminished. Moreover, a detailed analysis showed that the nanoparticles presence did not affect significantly the fluid momentum and energy distribution.

\subsection{Tapered Diffusion Flame Reactor with 1-4 Aerodynamic Lenses}

Figure 17 shows the streamlines pattern for the tapered reactors coupled to 2, 3 and 4 aerodynamic lenses at 0.95 atm operating (outlet) pressure. As observed in the previous cases, at 0.5 and 0.75 atm the streamlines were very similar. The lens system was added with the objective to obtain a narrower flow distribution at the outlet with the same operational conditions. Since at $1 \mathrm{~atm}$ the pressure difference was not sufficient to induce the flow through the orifice, cases at $0.95 \mathrm{~atm}$ were evaluated in order to minimize the operational cost associated with a high vacuum system. As can be noted, the presence of 2 or 3 lenses produced a pattern similar to the one observed when just one lens was present (as seen in Fig. 10), with larger recirculation zones near to the inlet. It is worth to note that the recirculation zone size was not affected by the second 


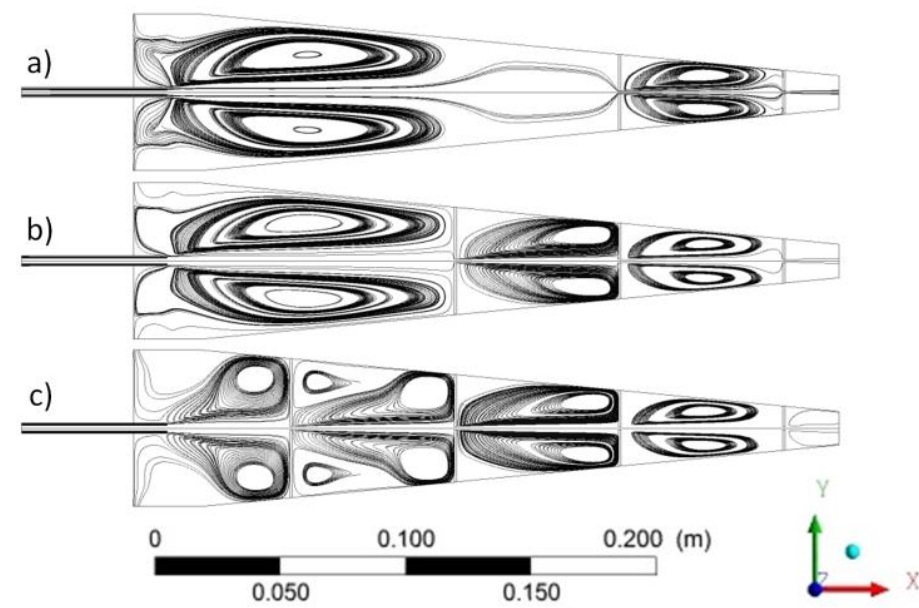

Fig. 17. Streamlines for operating pressure of $0.95 \mathrm{~atm}$ for the tapered reactor coupled to a) 2 b) 3 and c) 4 lenses. The orifices are positioned at $x=434, x=288$ and $x=142 \mathrm{~mm}$, respectively.

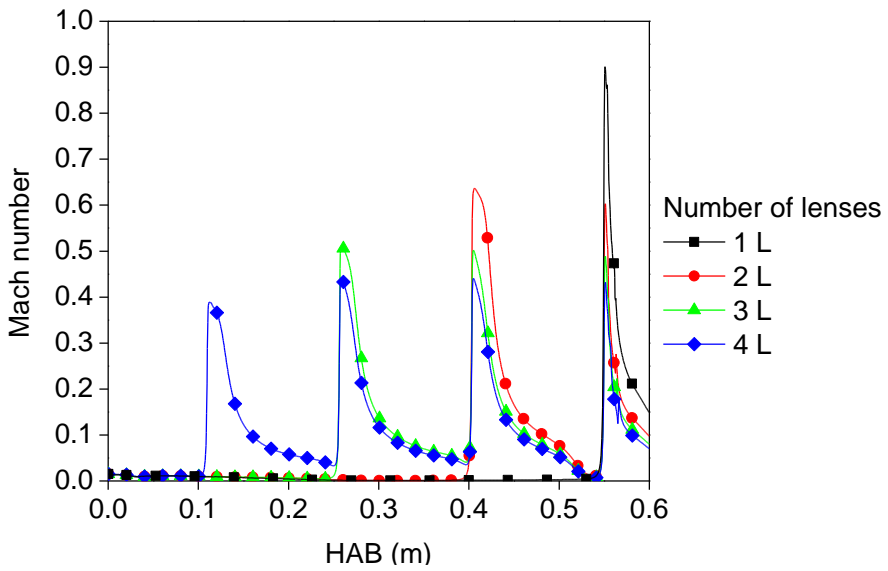

Fig. 18. Mach number profiles in height above the burner (HAB) for the tapered reactor coupled to 1-4 lenses considering an operating pressure of $0.5 \mathrm{~atm}$.

and third lens, but by the wall inclination and the mass flow restriction at the last orifice. When a fourth lens was added, the main recirculation zone was broken into two parts and small recirculation zones appeared between the lenses, which may generate hot spots and alter the heat transfer to the external wall.

Figure 18 illustrates the Ma curve along the reactor main axis at $0.5 \mathrm{~atm}$ operating pressure. It was observed that the profile was similar to the observed with the cases with just one orifice plate (Fig. 11). However, the maximum Ma number value reached was considerable lower (about 0.6 for $0.75 \mathrm{~atm}$ and 0.3 for $0.95 \mathrm{~atm})$ and all cases remained in the subsonic regime.

The presence of more than one orifice plate (multiple lens system) was expected to confine the particles closer to the reactor axis, as observed with a plane reactor (Klemz et al. 2017). However, closer to the reactor outlet all cases reached a similar flow distribution, as illustrated in Fig. 19 at 0.95 atm, which indicates that the cross sectional area reduction combined with just one orifice plate was suitable to focus the nanoparticles, even at operating pressures closer to the ambient pressure. The axial velocity is reduced as the number of lens increases due to the increase in the stagnation created by the recirculation regions.

The temperature profiles at 0.95 atm operating pressure are showed in Fig. 20. Again, the profiles for 0.5 and $0.75 \mathrm{~atm}$ were similar and were be omitted. As previously mentioned, the presence of more intense recirculation zones hampers the heat removal inside the tapered reactor, which leads to an increase in the average temperature in the reaction zone. Initially, it was observed a temperature increase due to the precursor consumption. After the reaction extinguish, the flow temperature remained approximately constant until the fluid passed through the lenses. Nevertheless, even for the reactor with 4 lenses, the fuel was completely consumed before it reached the first lens. Thereby the number of lenses increase did not directly affect the fuel conversion.

Based on the results presented in this section, it was possible to conclude that the presence of more than 
A. C. Klemz et al. / JAFM, Vol. 14, No. 1, pp. 201-214, 2021.

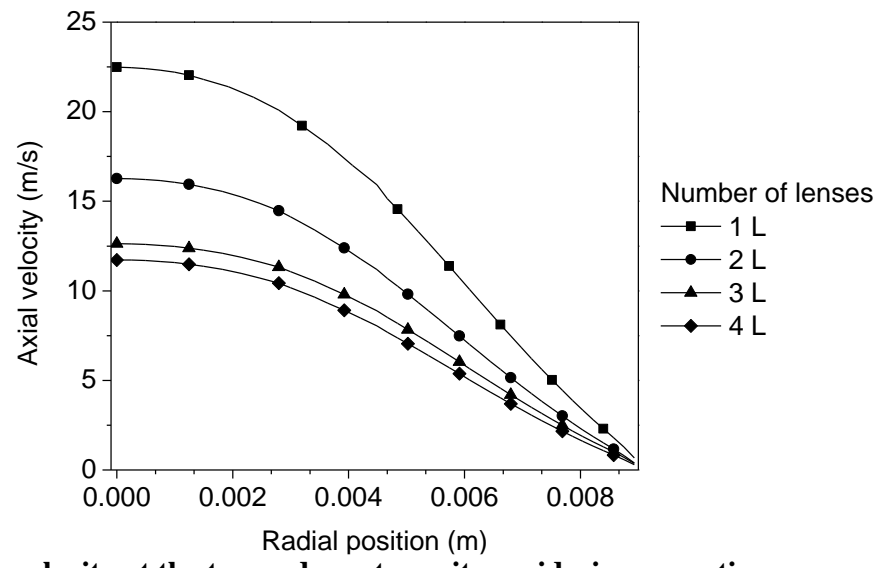

Fig. 19. Axial flow velocity at the tapered reactor exit considering operating pressures of 0.95 atm and the coupling of 1-4 lenses.

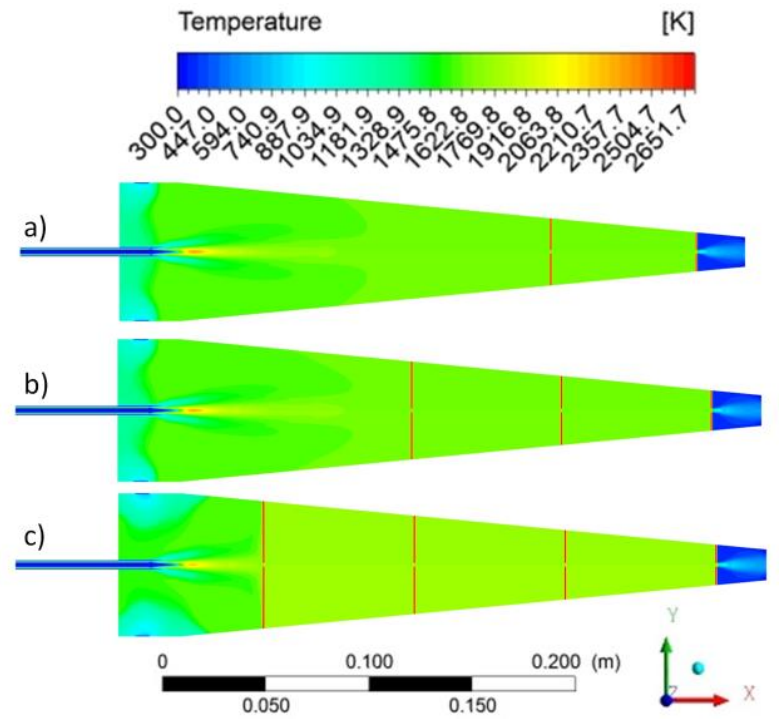

Fig. 20. Reaction flame of the tapered reactor considering an operating pressure of $0.95 \mathrm{~atm}$ and the coupling of a) 2 b) 3 and c) 4 lenses.

one orifice plate did not result in a significant improvement in the particle focusing or in any other characteristic of the system.

\section{CONCLUSION}

The combination of the gas phase synthesis with aerodynamic manipulation is a very promising approach for the production of nanostructured materials and devices. The ability to control the position, size and velocity of the nanoparticles is fundamental to achieve the best reactor operation mode and define the most efficient design for specific applications. In this study, the coupling of aerodynamic lenses to a new tapered diffusion flame reactor at different operational conditions was investigated. The results showed that the cross sectional area reduction by itself is suitable to focus the nanoparticles, even with an outlet reactor pressure close to the ambient pressure, since the flow constriction did not reduce the production rate. In this case, the particle distribution was controlled by a plug flow at the outlet. Nevertheless, the coupling of the tapered reactor with one aerodynamic lens showed a significant improvement in the main flow distribution, at the cost of an increase in the average temperature inside the reactor and an increase in the pressure drop due to the flow constriction. However, it was found that the presence of more than one lens did not add greater advantages on the flow distribution. The proposed design promoted a concentrated particles stream without the use of very low pressures at the system outlet, facilitating the system implementation.

\section{ACKNOWLEDGMENTS}

This study was financed in part by the Coordenação de Aperfeiçoamento de Pessoal de Nível Superior Brasil (CAPES) - Finance Code 001. The authors are 
grateful to LABSIN - Chemical Systems Numerical Simulation, for the available computational infrastructure.

\section{CONFLICT OF INTEREST}

The authors declare that they have no conflict of interest.

\section{REFERENCES}

Araoye, A. A., H. M. Badr and W. H. Ahmed (2017). Investigation of flow through multi-stage restricting orifices. Annals of Nuclear Energy 104, 75-90.

Athanassiou, E. K., R. N. Grass and W. J. Stark (2010). Chemical Aerosol Engineering as a Novel Tool for Material Science: From Oxides to Salt and Metal Nanoparticles. Aerosol Science and Technology 44(2), 161-172.

Barborini, E., S. Vinati, M. Leccardi, P. Repetto, G. Bertolini, O. Rorato, L. Lorenzelli, M. Decarli, V. Guarnieri, C. Ducati and P. Milani (2008). Batch fabrication of metal oxide sensors on micro-hotplates. Journal of Micromechanics and Microengineering 18(5), 055015.

Bongiorno, G., A. Podestà, L. Ravagnan, P. Piseri, P. Milani, C. Lenardi, S. Miglio, M. Bruzzi and C. Ducati (2006). Electronic properties and applications of cluster-assembled carbon films. Journal of Materials Science: Materials in Electronics 17(6), 427-441.

Chen, D. R. and D. Y. H. Pui (1995). Numerical and experimental studies of particle deposition in a tube with a conical contraction laminar-flow regime. Journal Of Aerosol Science 26(4), 563574.

Choi, H., S. Kang, W. Jung, Y. H. Jung, S. J. Park, D. S. Kim and M. Choi (2015). Controlled electrostatic focusing of charged aerosol nanoparticles via an electrified mask. Journal of Aerosol Science 88, 90-97.

Dahneke, B. and H. Flachsbart (1972). An aerosol beam spectrometer. Journal of Aerosol Science 3(5), 345-349.

Das, R. and J. D. Phares (2004). Expansion of an ultrafine aerosol through a thin-plate orifice. Journal of Aerosol Science 35(9), 1091-1103.

Deng, R., X. Zhang, K. A. Smith, J. Wormhoudt, D. K. Lewis and A. Freedman (2008). Focusing particles with diameters of 1 to 10 microns into beams at atmospheric pressure. Aerosol Science and Technology 42(11), 899-915.

Diederich, L., E. Barborini, P. Piseri, A. Podesta, P. Milani, A. Schneuwly and R. Gallay (1999). Supercapacitors based on nanostructured carbon electrodes grown by cluster-beam deposition. Applied Physics Letters 75(17), 2662-2664.

Fluent, A. (2011). Ansys Fluent Theory Guide. ANSYS Inc., USA, 15317(November 2013),
724-746. Retrieved from

http://scholar.google.com/

scholar?hl=en\&btnG=Search\&q=intitle:ANSY S+Fluent+Theory+Guide\#1

Gröhn, A. J., B. Buesser, J. K. Jokiniemi and S. E. Pratsinis (2011). Design of turbulent flame aerosol reactors by mixing-limited fluid dynamics. Industrial and Engineering Chemistry Research 50(6), 3159-3168.

Headrick, J. M., P. E. Schrader and H. A. Michelsen (2013). Radial-profile and divergence measurements of combustion-generated soot focused by an aerodynamic-lens system. Journal of Aerosol Science 58, 158-170.

Klemz, A. C., É. Fontana, A. A. U. de Souza and S. M. A. G. U. de Souza (2017). Analysis of heat and mass transfer in diffusion flame reactors coupled with aerodynamic lenses. Chemical Engineering Research and Design, 118, 215225.

Lee, S. H., Y. H. Kim, R. Deshpande, P. A. Parilla, E. Whitney, D. T. Gillaspie, K. M. Jones A. H. Mahan, S. Zhang and A. C. Dillon (2008). Reversible lithium-ion insertion in molybdenum oxide nanoparticles. Advanced Materials 20(19), 3627-3632.

Liu, P. S. K., R. Deng, K. A. Smith, L. R. Williams, J. T. Jayne, M. R. Canagaratna, K. Moore,T. B. Onasch, D. R. Worsnop and T. Deshler (2007). Transmission efficiency of an aerodynamic focusing lens system: Comparison of model calculations and laboratory measurements for the aerodyne aerosol mass spectrometer. Aerosol Science and Technology 41(8), 721-733.

Liu, P., P. J. Ziemann, D. B. Kittelson and P. McMurry H. (1995a). Generating particle beams of controlled dimensions and divergence: I. Theory of particle motion in aerodynamic lenses and nozzle expansions. Aerosol Science and Technology 22(3), 293-313.

Liu, P., P. J. Ziemann, D. B. Kittelson and P. McMurry P. H. (1995b). Generating Particle Beams of Controlled Dimensions and Divergence: II. Experimental Evaluation of Particle Motion in Aerodynamic Lenses and Nozzle Expansions. Aerosol Science and Technology 22(3), 314-324.

Mädler, L., A. Roessler, S. E. Pratsinis, T. Sahm, A. Gurlo, N. Barsan and U. Weimar (2006). Direct formation of highly porous gas-sensing films by in situ thermophoretic deposition of flame-made $\mathrm{Pt} / \mathrm{SnO} 2$ nanoparticles. Sensors and Actuators, B: Chemical 114(1), 283-295.

Mazza, T., E. Barborini, I. N. Kholmanov, P. Piseri, G. Bongiorno, S. Vinati, P. Milani, C. Ducati, D. Cattaneo, A. L. Bassi, C. E. Bottani, A. J. Taurino and P. Siciliano (2005). Libraries of cluster-assembled titania films for chemical sensing. Applied Physics Letters 87(10), 103108 .

Milani, P., P. Piseri, E. Barborini, A. Podesta and C. 
Lenardi (2001). Cluster beam synthesis of nanostructured thin films. Journal of Vacuum Science and Technology A 19(2001), 20252033.

Mueller, R., H. K. Kammler, S. E. Pratsinis, A. Vital, G. Beaucage and P. Burtscher (2004). Nonagglomerated dry silica nanoparticles. Powder Technology 140(1-2), 40-48.

Murphy, W. K. and G. W. Sears (1964). Production of Particulate Beams. Journal of Applied Physics 35(6), 1986.

Noriler, D., C. D. Rosebrock, L. Madler, H. F. Meier and U. Fritsching (2014). Influence of Atomization and Spray Parameters on the Flame Spray Process for Nanoparticle Production. Atomization and Sprays 24(6), 495-524.

Ochs, R., D. V. Szabó, S. Schlabach, S. Becker and S. Indris (2011). Development of nanocomposites for anode materials in Li-ion batteries. Physica Status Solidi (A) 208(2), 471473.

Piseri, P., H. V. Tafreshi and P. Milani (2004). Manipulation of nanoparticles in supersonic beams for the production of nanostructured materials. Current Opinion in Solid State and Materials Science 8(3-4), 195-202.

Qiu, J., J. H. Judy, D. Weller and J. Wang (2005). Toward the direct deposition of L1[sub 0] FePt nanoparticles. Journal of Applied Physics 97(2005), 10J319.

Simpson, A. and V. V. Ranade (2018). Modelling of hydrodynamic cavitation with orifice: Influence of different orifice designs. Chemical Engineering Research and Design 136, 698711 .

Torabmostaedi, H. and T. Zhang (2014). Effect of nozzle geometry and processing parameters on the formation of nanoparticles using FSP. Chemical Engineering Research and Design 92(11), 2470-2478.

Torabmostaedi, H., T. Zhang, P. Foot, S. Dembele and C. Fernandez (2013). Process control for the synthesis of $\mathrm{ZrO} 2$ nanoparticles using FSP at high production rate. Powder Technology 246, 419-433.

Wang, X., A. Gidwani, S. L. Girshick and P. H. McMurry (2005a). Aerodynamic focusing of nanoparticles: II. Numerical simulation of particle motion through aerodynamic lenses. Aerosol Science and Technology 39(7), 624636.
Wang, X., F. E. Kruis and P. H. McMurry (2005b) Aerodynamic Focusing of Nanoparticles: I. Guidelines for Designing Aerodynamic Lenses for Nanoparticles. Aerosol Science and Technology 39(7), 611-623.

Wang, X. and P. H. McMurry (2006). A design tool for aerodynamic lens systems. Aerosol Science and Technology 40(5), 320-334.

Wegner, K, P. Piseri, H. V. Tafreshi and P. Milani (2006). Cluster beam deposition: a tool for nanoscale science and technology. Journal of Physics D: Applied Physics 39(22), R439-R459.

Wegner, K, S. Vinati, P. Piseri, A. Antonini, A. Zelioli, E. Barborini, C. Ducati and P. Milani (2012). High-rate production of functional nanostructured films and devices by coupling flame spray pyrolysis with supersonic expansion. Nanotechnology 23(18), 185603.

Wegner, K., W. J. Stark and S. E. Pratsinis (2002). Flame-nozzle synthesis of nanoparticles with closely controlled size, morphology and crystallinity. Materials Letters 55(5), 318-321.

Yu, M., J. Lin and T. Chan (2008). Numerical simulation of nanoparticle synthesis in diffusion flame reactor. Powder Technology 181(1), 9-20.

Yu, M. Z., J. Z. Lin and T. L. Chan (2008). Effect of precursor loading on non-spherical $\mathrm{TiO} 2$ nanoparticle synthesis in a diffusion flame reactor. Chemical Engineering Science 63(9), 2317-2329.

Zhang, L., J. Shao, X. Chen, J. Zhang and Q. Si (2016). Design and evaluation of aerodynamic lens system for focusing sub-10nm nanoparticles. Applied Physics A: Materials Science and Processing 122(11), 1-6.

Zhang, X., K. A. Smith, D. R. Worsnop, J. Jimenez, J. T. Jayne and C. E. Kolb (2002). A Numerical Characterization of Particle Beam Collimation by an Aerodynamic Lens-Nozzle System: Part I. An Individual Lens or Nozzle. Aerosol Science and Technology 36(5), 617-631.

Zhang, X., K. A. Smith, D. R. Worsnop, J. L. Jimenez, J. T. Jayne, C. E. Kolb, J. Morris and P. Davidovits (2004). Numerical characterization of particle beam collimation: Part II integrated aerodynamic-lens-nozzle system. Aerosol Science and Technology 38(6), 619-638. 